

\title{
Prevalence of musculoskeletal disorder in electricity lineman in city Faisalabad, Pakistan
}

Received: 26 July 2021

Accepted: 13 September, 2021

Published: 14 September, 2021

*Corresponding authors: Umair Arif, Lecturer statistics, University of Faisalabad, Pakistan,

E-mail:Umair.arif@tuf.edu.pk

Keywords: Work related musculoskeletal disorders

https://www.peertechzpublications.com

Check for updates

\section{Amna Noor ${ }^{1}$, Umair Arif ${ }^{2 \star}$, Sulman Aslam ${ }^{1}$, Raees Sabir ${ }^{1}$, Ammar Ahmad Sohail', Hareem Aslam ${ }^{1}$, Mahnoor $\mathrm{Ch}^{1}$ and Syed Muhammad Ali raza ${ }^{1}$}

'Student of Physical Therapy, University of Faisalabad, Pakistan

${ }^{2}$ Lecturer statistics, University of Faisalabad, Pakistan

\begin{abstract}
Objectives: The objective of this research is to discover the trends of work-related musculoskeletal disorders that are prevalent in the linemen population, as well as the occupational activities that put linemen at risk of developing WRMDs.
\end{abstract}

Methodology: The study included 50 male linemen employed in FASCO, who performed various field tasks in a Faisalabad city Pakistan. Age group included in the study between 20 to 40 years. Chi square test was applied to check association between daily life and incidence of symptoms.

Results: There is no significance associations were founded between age and tasks of linemen with p-value 0.431 . There is significance association was founded between comfort and their tasks with p-value 0.002 . There is significance association was founded between body region and their tasks with $\mathrm{p}$-value 0.001 .

Conclusion: MSDs in body areas other than the back were found in our investigation, particularly in the shoulders and knees. We also identified high-risk tasks that would require more investigation and management.

\section{Introduction}

Musculoskeletal disorders are common among electricity linemen in the city of Faisalabad. Linemen, also called as power-line staff, are individuals who deal with electricity in various processes such as troubleshooting, tracking, and fixing overhead power stations. The working condition of linemen is said to be dangerous because the essence of the profession requires electricity, which can lead to electrocution and death during work time [1]. Aside from the risk of electrocution, Work-Related Musculoskeletal Disorders (WRMDs) amongst linemen have become a growing problem in recent decades of the physically challenging job activities [2]. Work-related musculoskeletal conditions arise as a result of physical risk variables in the workplace and job assignments. The National Institute of Occupational Safety and Health (NIOSH) has found compelling data linking physical health risks and job assignments to the emergence of work-related musculoskeletal disorders [3]. According to an Electric Power Research Institute (EPRI) survey, the lineman occupation has the highest proportion (17.7 percent) of medical insurance premiums as compared to other forms of electricity-related occupations. Nonetheless, the sequence of WRMDs in different body parts among linemen has not been extensively studied. As a result, there are drawbacks and difficulties in developing a healthcare intervention policy for the prevention and treatment of WRMDs in lineman community [4]. The electric power industry's overhead and underground line work is physically demanding and can expose employees to musculoskeletal disorders (WRMDs), in upper extremity specifically [5].

\section{Objective}

The objective of this research is to discover the trends of work-related musculoskeletal disorders that are prevalent in the linemen population, as well as the occupational activities that put linemen at risk of developing WRMDs. 


\section{Material and methodology}

The study included 50 male linemen employed in FASCO, who performed various field tasks in a Faisalabad city Pakistan. Age group included in the study between 20 to 40 years. The project was approved by the Research Ethics Committee of The University of Faisalabad.

The distribution linemen were divided into three groups according to the type of tasks they performed

1. Live Line Linemen (LLL): Linemen who work on the high- and low-voltage distribution networks in real time.

2. Maintenance/Emergency Linemen (MEL): Linemen who respond to emergencies and pre-programmed services. They are in charge of checking and maintaining the medium- and low-voltage networks, as well as maintaining street lights. The MEL team employs ladders to complete duties, and the linemen are belted to the pole or ladder. There are three different ladder sizes to choose from: Three ladder sizes are used: a central ladder $(10.2 \mathrm{~m})$ linked to the vehicle but not carried by the linemen; a portable ladder $(7.8 \mathrm{~m}, 31 \mathrm{~kg})$ that must be carried by two individuals; and a portable ladder $(6.6 \mathrm{~m}$, 26kg) carried by a single line-man.

3. Commercial Linemen (CL): Inspection linemen are in charge of cutting and restoring the energy supply as well as maintaining and removing energy consumption metres. These tasks necessitate the use of fewer ladders and less exertion, as well as the use of tools on occasion.

\section{Procedures}

The data was collected with the use of questionnaires between june $10^{\text {th }}$ to August $25^{\text {th }}, 2018$. Before the commencement of the work shift, the questionnaires were administered in groups of no more than five people in private places. The participants were educated about the study's general protocols and signed a consent form ensuring data confidentiality. The questionnaire was refined in two pilot studies to obtain the final version. The first pilot research was done with the company's head engineer, who proposed some revisions to make the questions more clear for the staff. The second pilot research involved four lineman who rated the questions for clarity. The first section of the questionnaire consisted of general demographic and occupational questions (age, gender, height, weight) (time of employment in the company description of previous and current tasks, time in the same job function, exposure to and duration of certain tasks in relation to the work week, such as: travel, walking, preparation of job site and observation Work leave, general health, fitness level, and housework were also covered in the survey. This discomfort is unlikely to be the result of a catastrophic injury. After that, the workers were asked to classify the symptoms using the McGill pain questionnaire, which had already been translated and verified into Portuguese 12. The final section of the questionnaire included numerical pain scales 13 ranging from 0 to 10 that were used to rate the level of discomfort in each body region at the time of the assessment. The shoulder region was the most afflicted by musculoskeletal complaints, according to a prior study of the questionnaire answers. A new data collection was set up using the Portuguese version of the optional work module of the DASH questionnaire14 to assess the impact of musculoskeletal symptoms on worker performance. Due to the small number of individuals in each group, the score was calculated for a descriptive comparison between the symptomatic groups according to the analytic technique of this questionnaire. To determine how much the workers' musculoskeletal issues were hurting them, data on work leave and absences were gathered from the company's human resource department. To supplement the examination, the examiners filmed the occupational actions they were evaluating on video. The examiners identified the WMSD risk factors present during the activities.

\section{Statistical analysis}

Descriptive statistical analysis was performed in mean and standard deviation form Data was analyzed on SPSS version 23 and checked significance at $\alpha=0.05$.

\section{Results}

Out of 50 linemen 8 were belong to age group 20-25 years, 15 were belongs to $25-30$ years, 17 were belongs to age group 30-35 years and 10 were belongs to age group 35- 40 years. Mean \pm S.D was $32.91 \pm 2.71$ years (Figure 1 )

Out of 50 linemen 10 had matric qualification, 25 had intermediate qualification, 15 had graduation level qualification (Figure 2).

Out of 50 linemen $17(34 \%)$ had less than 3 year working experience, $10(20 \%)$ had 3 year experience and $23(46 \%)$ had more than 3 year working experience (Figure 3). Out of 50 linemen $16(32 \%$ ) perform Live Line (LLL), 25(50\%) perform Maintenance/Emergency (MEL), 9(18\%) perform Commercial Linemen (CL) (Figure 4). This table shows association between tasks of linemen with their age and their comfort. There is no significance association were founded between age and tasks of linemen with $\mathrm{p}$-value 0.431 . There is significance association was founded between comfort and their tasks with p-value

\section{Age distribution}

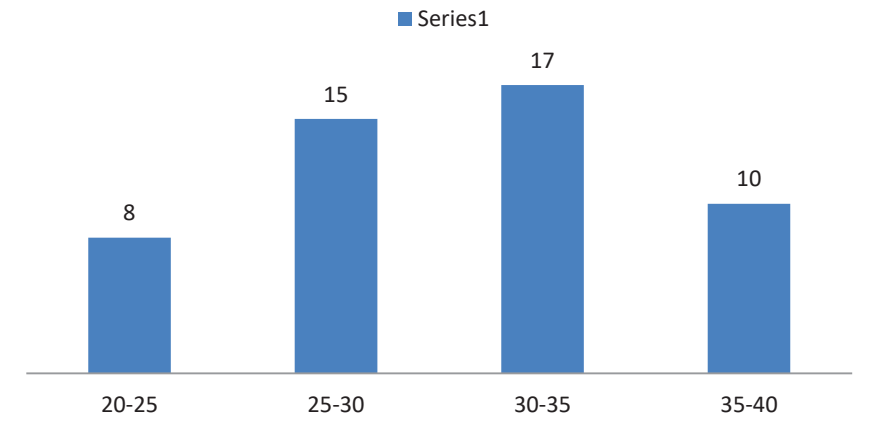

Figure 1: Age Distribution

Citation: Noor A, Arif U, Aslam S, Sabir R, Sohail AA, et al. (2021) Prevalence of musculoskeletal disorder in electricity lineman in city Faisalabad, Pakistan. Ann 
0.002 (Table 1). This table shows association between tasks of linemen with pain on their different body part region. There is significance association was founded between body region and their tasks with p-value 0.001 (Table 2).

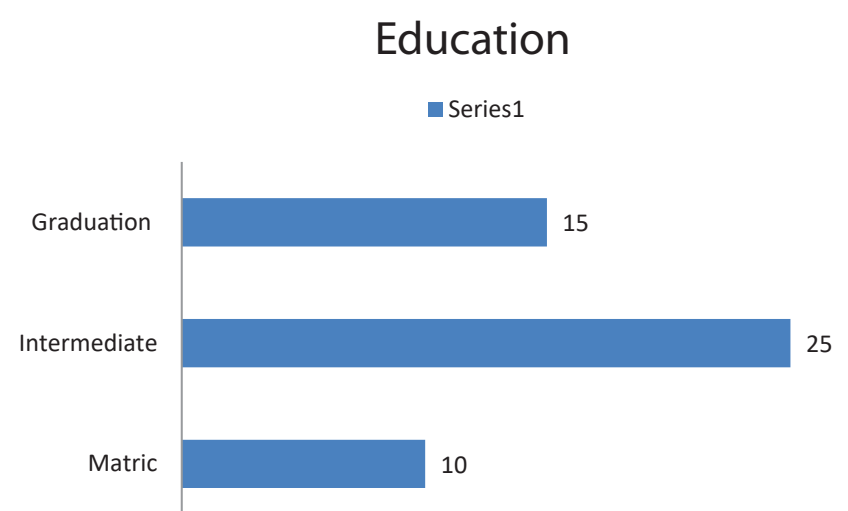

Figure 2: Education level.

\section{Working Experience}

$$
\text { घ<3 year } \quad 3 \text { year } \quad>3 \text { year }
$$

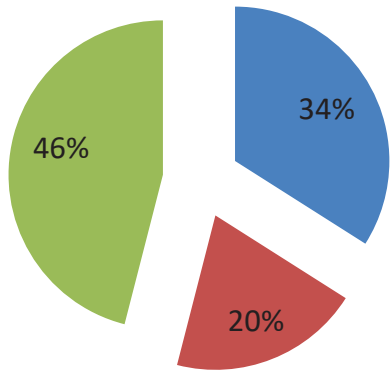

Figure 3: Working Experience.

\section{tasks of Linemen}

$\square \mathrm{LLL} \square \mathrm{LM} \square \mathrm{CL}$

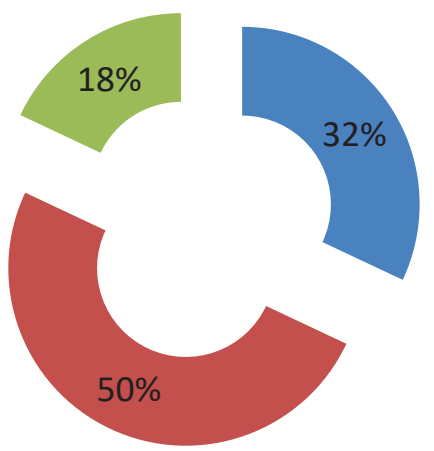

Figure 4: Types of linemen tasks.
Table 1: Association between types of linemen tasks with different variables.

\begin{tabular}{|c|c|c|c|c|c|c|}
\hline & & Type & Liner & Tas & & \\
\hline \multirow{6}{*}{ Age } & & LLL & MEL & $\mathrm{CL}$ & TOTAL & $\mathrm{p}$-value \\
\hline & $20-25$ & 2 & 5 & 1 & 8 & \multirow{5}{*}{0.431} \\
\hline & $25-30$ & 5 & 7 & 3 & 15 & \\
\hline & $30-35$ & 5 & 9 & 3 & 17 & \\
\hline & $35-40$ & 4 & 4 & 2 & 10 & \\
\hline & Total & 16 & 25 & 9 & 50 & \\
\hline \multirow{3}{*}{ Discomfort } & Yes & 11 & 20 & 8 & 39 & \multirow{3}{*}{0.002} \\
\hline & No & 5 & 5 & 1 & 11 & \\
\hline & Total & 16 & 25 & 9 & 50 & \\
\hline
\end{tabular}

Table 2: Association between types of linemen tasks with Body Region.

\begin{tabular}{|c|c|c|c|c|c|c|}
\hline & \multicolumn{5}{|c|}{ Types of Linemen Tasks } & \\
\hline \multirow{5}{*}{ Body Region } & & LLL & MEL & $\mathrm{CL}$ & TOTAL & p-value \\
\hline & Shoulder & 4 & 8 & 3 & 15 & \multirow{4}{*}{0.001} \\
\hline & Spine & 6 & 15 & 2 & 23 & \\
\hline & Knee & 6 & 2 & 4 & 12 & \\
\hline & Total & 16 & 25 & 9 & 50 & \\
\hline
\end{tabular}

\section{Discussion}

The current study observed significant prevalence of MSD among electricity workers, particularly among electricity linemen. Linemen were primarily impacted in the back and shoulder regions. Six out of every ten FESCO employees have a musculoskeletal disorder. The main complaint was pain and muscle weakness. Working experience and education may all be factors in this condition.

Moriguchi CS, et al. conducted a study in 2009, they found a significant frequency of musculoskeletal problems among electric energy distributing electricians in the area of the state of Sao Paulo. The number of symptomatic employees changed according to electrician activity in regard to shoulder problems [6] In current study, significant association was found between body region and their tasks.

In the current study, the most common site of pain was spine region which is similar to previous findings among electrical workers [7]. The prevalence of back pain in MEL was high and after that was the shoulder pain. This shows the strong association among tasks and body region.

In our study, we investigated the level of discomfort during activity in different field linemen related to tasks. The high level of discomfort was noted in MEL and less in CL. There is significant association found among level of discomfort and tasks.

In Live Line Linemen the prevalence of both knee and spine region pain was equally high as compared to shoulder region. This conclusion is consistent with the findings of Merlino, et al. [8], who found a significant prevalence of knee pain [9-18].

\section{Conclusion}

MSDs in body areas other than the back were found in our investigation, particularly in the shoulders and knees. We also identified high-risk tasks that would require more investigation and management.

Citation: Noor A, Arif U, Aslam S, Sabir R, Sohail AA, et al. (2021) Prevalence of musculoskeletal disorder in electricity lineman in city Faisalabad, Pakistan. Ann Musculoskelet Med 5(2): 009-012. DOI: https://dx.doi.org/10.17352/amm.000026 


\section{Recommendation}

Ergonomically associated factors should be investigated in future studies in order to establish a holistic health strategy aimed towards the linemen population. i.e., lineman platform and safety belt have been redesigned, job task redesign, fitness program implementation and ergonomic training.

\section{Limitation}

1. In this study, additional causal risk variables such as psychological and individual health risks were missing.

2. The research only included male participants.

\section{References}

1. Brun JP (1995) Work activity and subjectivity: A behind-the-scenes look at the work of linemen. Relations industrielles/Industrial Relations. 50: 811-825. Link: https://bit.ly/3hpUKUM

2. Moriguchi CS, Alencar JF, Miranda-Júnior LC, Coury HG (2009) Musculoskeletal symptoms among energy distribution network linemen. Brazilian Journal of Physical Therapy 13: 123-129. Link: https://bit.ly/3955y6e

3. Bernard BP, Putz-Anderson V (1997) Musculoskeletal disorders and workplace factors; a critical review of epidemiologic evidence for work-related musculoskeletal disorders of the neck, upper extremity, and low back. Link: https://bit.ly/3z6IFev

4. Padmanathan V, Joseph L, Omar B, Nawawi R (2016) Prevalence of musculoskeletal disorders and related occupational causative factors among electricity linemen: a narrative review. Int J Occup Med Environ Health 29: 725 734. Link: https://bit.ly/3z80arM

5. Marklin RW, Lazuardi L, Wilzbacher JR (2004) Measurement of handle forces for crimping connectors and cutting cable in the electric power industry. International Journal Industrial Ergonomics 34: 497-506. Link: https://bit.ly/2XbfPLx

6. Moriguchi CS, Alencar JF, Miranda-Júnior LC, Coury HG (2009) Musculoskeletal symptoms among energy distribution network linemen. Brazilian Journal of Physical Therapy 13: 123-129. Link: https://bit.ly/3955y6e

7. Moriguchi CS, Carnaz L, Alencar JF, Júnior LC, Granqvist L, et al. (2011) Postures and movements in the most common tasks of power line workers. Ind Health 49: 482-491. Link: https://bit.ly/3C8lqkU

8. Merlino LA, Rosecrance JC, Anton D, Cook TM (2003) Symptoms of musculoskeletal disorders among apprentice construction workers. Appl Occup Environ Hyg 18: 57-64. Link: https://bit.ly/393gRvK

9. Roli D, Ali I, Neekhra V (2020) Work Related Musculoskeletal Disorders in Electrical, Telecommunication and Instrument Mechanics of Armed forces. International Journal of Occupational Safety and Health 10: 18-27. Link: https://bit.ly/3tAn37U

10. Pirposhteh EA, Karim A, Abadi AS (2019) Evaluation the Prevalence of Musculoskeletal Disorders Among the Medical Staff of Selected hospitals of Shahid Beheshti University of Medical Sciences in 2018. Journal of Safety Promotion and Injury Prevention 7: 69-77. Link: https://bit.ly/3tE25VD

11. Peláez S, Zea C, Mondragón I, García R, Hernández G (2020) Comparison of Muscular Activity Analysis for Electrical Technicians in High Voltage Lines Using Exoskeleton in the Colombian Industry, Enel-Codensa Study Case. InInternational Conference on Human Interaction and Emerging Technologies 435-440. Link: https://bit.ly/2XcMGQI
12. Gómez-Galán M, Perez-Alonso J, Callejon-Ferre AJ, López-Martínez J (2017) Musculoskeletal disorders: OWAS review. Ind Health 55: 314-337. Link: https://bit.ly/3hogi4g

13. Gómez-Galán $\quad M$, Pérez-Alonso J, Callejón-Ferre ÁJ, SánchezHermosilla-López J (2018) Assessment of postural load during melon cultivation in Mediterranean greenhouses. Sustainability 10: 2729. Link: https://bit.ly/3z6p500

14. Ramírez-Pozo EG, Montalvo Luna M (2019) Frecuencia de trastornos musculoesqueléticos en los trabajadores de una refinería de Lima, 2017. Anales de la Facultad de Medicina 80: 337-341. Link: https://bit.ly/3hrv2iV

15. Fullagar HH, McCunn R, Murray A (2017) Updated review of the applied physiology of American college football: Physical demands, strength and conditioning, nutrition, and injury characteristics of america's favorite game. International Journal Sports Physiology performance 12: 1396-1403. Link: https://bit.ly/2XbMPDX

16. Owora AH, Kmush BL, Walia B, Sanders S (2018) A systematic review of etiological risk factors associated with early mortality among National Football League players. Orthop J Sports Med 6: 2325967118813312. Link: https://bit.ly/2YT38pB

17. Tran A, Kappa J, Smith E, Hoy M, Farrar J, et al. (2019) The Effect of Turf Toe Injuries on Player Performance in the National Football League. lowa Orthop $J$ 39: 35-39. Link: https://bit.ly/3nq6NFF

18. Sarac N, Haynes W, Pedroza A, Kaeding C, Borchers J (2017) Lifetime prevalence of injuries in incoming division I collegiate football players. Phys Sportsmed 45: 458-462. Link: https://bit.ly/2YLrcKR

Discover a bigger Impact and Visibility of your article publication with Peertechz Publications

\section{Highlights}

* Signatory publisher of ORCID

- Signatory Publisher of DORA (San Francisco Declaration on Research Assessment)

* Articles archived in worlds' renowned service providers such as Portico, CNKI, AGRIS, TDNet, Base (Bielefeld University Library), CrossRef, Scilit, J-Gate etc.

* Journals indexed in ICMJE, SHERPA/ROMEO, Google Scholar etc.

* OAl-PMH (Open Archives Initiative Protocol for Metadata Harvesting)

* Dedicated Editorial Board for every journal

* Accurate and rapid peer-review process

* Increased citations of published articles through promotions

* Reduced timeline for article publication

Submit your articles and experience a new surge in publication services (https://www.peertechz.com/submission).

Peertechz journals wishes everlasting success in your every endeavours.

Copyright: @ 2021 Noor A, et al. This is an open-access article distributed under the terms of the Creative Commons Attribution License, which permits unrestricted use distribution, and reproduction in any medium, provided the original author and source are credited.

Citation: Noor A, Arif U, Aslam S, Sabir R, Sohail AA, et al. (2021) Prevalence of musculoskeletal disorder in electricity lineman in city Faisalabad, Pakistan. Ann Musculoskelet Med 5(2): 009-012. DOI: https://dx.doi.org/10.17352/amm.000026 